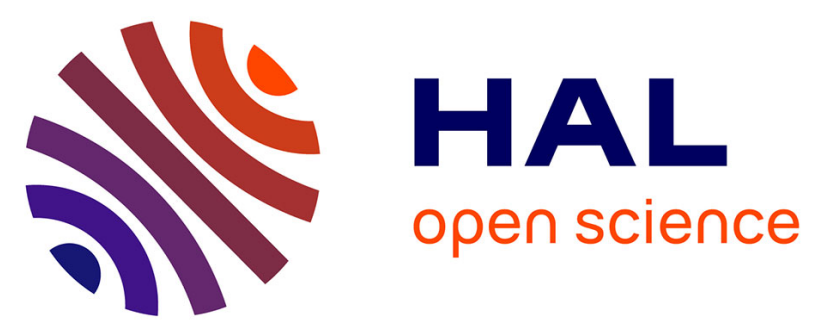

\title{
DETERMINATION OF CONSTANTS AND COMPARISON OF RESULTS FOR VARIOUS CONSTITUTIVE MODELS
}

T. Holmquist, G. N. Johnson

\section{- To cite this version:}

T. Holmquist, G. N. Johnson. DETERMINATION OF CONSTANTS AND COMPARISON OF RESULTS FOR VARIOUS CONSTITUTIVE MODELS. Journal de Physique IV Proceedings, 1991, 01 (C3), pp.C3-853-C3-860. 10.1051/jp4:19913119 . jpa-00249922

\section{HAL Id: jpa-00249922 \\ https://hal.science/jpa-00249922}

Submitted on 1 Jan 1991

HAL is a multi-disciplinary open access archive for the deposit and dissemination of scientific research documents, whether they are published or not. The documents may come from teaching and research institutions in France or abroad, or from public or private research centers.
L'archive ouverte pluridisciplinaire $\mathbf{H A L}$, est destinée au dépôt et à la diffusion de documents scientifiques de niveau recherche, publiés ou non, émanant des établissements d'enseignement et de recherche français ou étrangers, des laboratoires publics ou privés. 


\title{
DETERMINATION OF CONSTANTS AND COMPARISON OF RESULTS FOR VARIOUS CONSTITUTIVE MODELS
}

\author{
T.J. HOLMQUIST and G.R. JOHNSON \\ Alliant Techsystems Inc., 7225 Northland Drive, Brooklyn Park. \\ MN 55428, U.S.A
}

\begin{abstract}
The ability to compare different constitutive models has been difficult in the past because the constants associated with these models are developed using different methods and test data. This work presents an explicit, consistent procedure for which constants can be determined for different constitutive models using the same test data base. This allows for a direct comparison of the models to be made independent of the material constants. Using this procedure, constants are determined for four material models: Johnson-Cook, Modified Johnson-Cook, Zerilli-Armstrong, and a Combined Model (from Johnson-Cook and Zerilli-Armstrong) using two materials: OFHC Copper and Armco Iron. Comparisons are made between the different models by simulating Cylinder Impact experiments using the EPIC code.
\end{abstract}

\section{INTRODUCTION}

It is of interest to compare various constitutive models for use in computer codes. There are currently many different constitutive models available that describe the dynamic behavior of materials. Associated with these models are material constants which are required to describe the behavior of specific materials. The ability of constitutive models to describe material behavior is, therefore, a combined function of model formulation and the values of the associated constants. The objectives of this work are to develop a procedure by which constants can be obtained, for different constitutive models, using the same test data base, and to then compare the results of the different models. This will allow for material models to be compared to one another without bias, and for conclusions to be drawn as to which models may offer advantages. This procedure also provides a means for obtaining material constants for various constitutive models.

\section{DESCRIPTION OF MATERIAL MODELS}

Four material models are evaluated in this study. All models are taken to have five free constants to ensure consistent comparison. The models evaluated are the Johnson-Cook, Zerilli-Armstrong, Modified Johnson-Cook, and a Combined Model.

a. Johnson-Cook

The Johnson-Cook model represents an cmpirical relationship for the von Mises flow stress /1/.

$$
\sigma=\left[A+B \varepsilon^{n}\right]\left[1+C l n \dot{\varepsilon}^{*}\right]\left[1-T^{*} m\right]
$$

where $\varepsilon$ is the equivalent plastic strain, $\dot{\varepsilon}^{*}=\dot{\varepsilon} / \dot{\varepsilon}_{\mathrm{O}}$ is the dimensionless plastic strain rate for $\dot{\varepsilon}_{\mathrm{O}}=1.0 \mathrm{~s}^{-1}$, and $\mathrm{T}^{*}$ is the homologous temperature. The constants are $\mathrm{A}, \mathrm{B}, \mathrm{C}, \mathrm{n}$ and $\mathrm{m}$.

\section{b. Zerilli-Armstrong}

The Zerilli-Armstrong model represents a more physically based relationship based on dislocation mechanics $/ 2 /$. Constitutive equations for both face centered cubic (fcc) and body centered cubic (bcc) materials have been developed.

For this study, il is desirable to have models with five constants. This provides consistency between models and ensures that a consistent technique to determine constants can be applied. Small modifications to the Zerilli-Armstrong models werc required to obtain models with five constants. Care was taken to modify the models without reducing model integrity. The models for the von Mises flow stress, for face centered cubic (fcc) and body center cubic (bcc) materials are cxpressed as 


$$
\begin{aligned}
& \sigma=C_{0}+C_{2} \varepsilon^{n}\left[\operatorname{EXP}\left(-C_{3} T+C_{4} T \ln \dot{\varepsilon}\right)\right] \\
& \sigma=C_{0}+C_{1}\left[\operatorname{EXP}\left(-C_{3} T+C_{4} T \ln \dot{\varepsilon}\right)\right]+C_{5} \varepsilon^{n}
\end{aligned}
$$

where $\varepsilon$ is the equivalent plastic strain, $\dot{\varepsilon}$ is the plastic strain rate, and $T$ is the absolute temperature. For this study, the five material constants for the fcc model are $\mathrm{C}_{0}, \mathrm{C}_{2}, \mathrm{C}_{3}, \mathrm{C}_{4}$, and $\mathrm{n}$; and for the bcc model, $\mathrm{C}_{1}, \mathrm{C}_{3}, \mathrm{C}_{4}, \mathrm{C}_{5}$, and $\mathrm{n}$. The original model for fcc materials sets $n=1 / 2$, but it is taken as a free constant here. For bcc materials, $C_{0}$ is as specified by Zerilli and Armstrong $12 \%$.

\section{c. Modified Johnson-Cook}

The Modified Johnson-Cook model incorporates a simple modification to the Johnson-Cook model to better represent the strain rate effect. There is evidence that the strain rate influence on material strength is not a linear function of the natural $\log$, as the Johnson-Cook model indicates, but rather an exponential function $13 /$. To better model this behavior, an exponential strain rate function was incorporated into the Johnson-Cook model and it is expressed as

$$
\sigma=\left[A+B \varepsilon^{n}\right]\left[\ddot{\varepsilon}^{*} C\right]\left[1-T^{*} m\right]
$$

where the parameter and constant definitions are the same as for the Johnson-Cook model.

\section{d. Combined}

The Combined Model combines the yield and strain hardening portion of the Johnson-Cook model with the temperature and strain rate portion of the Zerilli-Armstrong model. There is evidence that the temperature and strain rate effect is coupled $/ 4 /$. The objective of the Combined Model is to better represent the coupled behavior of the temperature and strain rate effect. The Combined Model has the following form:

$$
\sigma=\left[\mathrm{A}+\mathrm{B} \varepsilon^{\mathrm{n}}\right]\left[\operatorname{EXP}\left(-\mathrm{C}_{3} \mathrm{~T}+\mathrm{C}_{4} \mathrm{~T} \ln \dot{\varepsilon}\right)\right]
$$

The five constants are $A, B, n, C_{3}$, and $C_{4}$ as defined in the previous models; and the strain, strain rate and absolute temperature are represented by $\varepsilon, \dot{\varepsilon}$, and $T$, respectively.

\section{TEST DATA}

The materials used for this study are OFHC copper, and Armco iron. These materials were chosen because of the large test data base available and the variation in material behavior $/ 1$. The test data used are obtained from torsion and tension tests over a wide range of strains, strain rates, and temperatures.

Tension data are comprised of dynamic Hopkinson pressure bar tests over a range of temperatures, and quasi-static tension tests at ambient temperature. At large tensile strains, after necking has begun, the net tensile stress is greater than the tensile flow stress due to the presence of hydrostatic tension caused by the geometry in the neck region. The quasi-static tension data are corrected for this effect by applying the Bridgman correction factor $/ 5 /$. This approximates the true flow stress of the material.

The torsion data are comprised of quasi-static and dynamic torsion tests at room temperature. The torsional stress-strain data are converted to equivalent tensile stress-strain data by using the von Mises flow rule. This gives $\sigma=\sqrt{3} \tau$ and $\varepsilon=\gamma / \sqrt{3}$, where $\sigma$ and $\varepsilon$ are the tensile stress and strain, and $\tau$ and $\gamma$ are the torsional stress and strain. Because real materials do not always obey the von Mises flow rule, the test data were separated into two sets, one comprised of all tension data and the other of mostly torsion (equivalent tension) data. Constants for the models were derived using each set of data. The top two sets of data in Figure 1 are tension data only, and the bottom sets are primarily torsion data. Because material behavior is primarily a function of strain, strain rate, and temperature, the test data were chosen to capture a variation of these effects. Due to the lack of high temperature torsion data, high temperature Hopkinson bar tensile tests were used. This is shown in the bottom set of data in Figure 1, and thus, is referred to as torsion/tension data.

\section{DETERMINATION OF CONSTANTS}

Five constants are required for each of the four constitutive models. These constants are determined from the test data shown in Figure 1. The approach is to define five data points from the test data that cover a range of strains, strain rates, and temperatures. Five data points are defined for tension and torsion/tension data, for each material, and are shown in Figure 1. Data points 1 to 3 are chosen to describe the flow stress behavior at constant temperature and strain rate. Data point 1 is the yield stress, and points 2 and 3 determine the strain hardening behavior. Data points 4 and 5 are chosen to capture the strain rate and temperature effects. At each point, the stress, strain, strain rate, and temperature are known. The data points, from which the constants are determined, are given in Table 1 . 


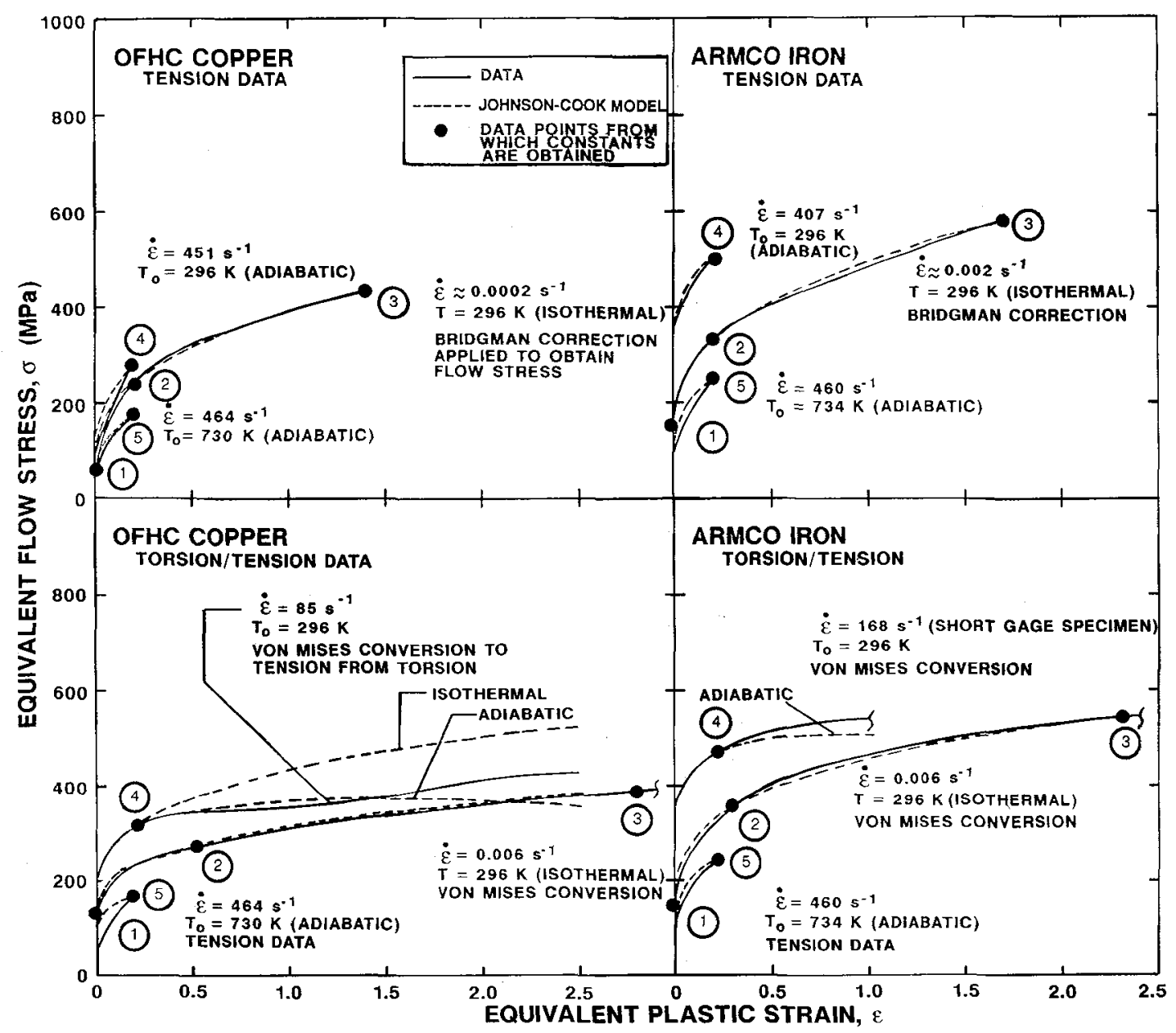

Figure 1. Tension and torsion test data from which the constants are obtained

The constants for all the models are determined in the same manner. The values of stress, strain, strain rate, and temperature are input into the model of interest for each of the five data points. This produces a series of five equations and five unknowns, the unknowns being the model constants. The resulting constants are shown in Table 2 , and the corresponding adiabatic stress-strain relationships are shown in Figure 2.

Figure 2 shows that the models behave differently depending on which set of test data is used to obtain material constants. This is most evident in the strain rate effect of OFHC copper. The largest difference between the models is the strain rate effect. How each model behaves relative to strain rate is shown in Figure 3. The Zerilli-Armstrong model consistently predicts the greatest strain rate effect while the Johnson-Cook model predicts the least amount. The responses in Figure 3 were generated at a constant strain; if other strain values were used the responses would change. Armco iron shows the greatest strain rate effect, which is consistent with test data /1/. 
Table 1. Test data at five selected conditions, from which the constants are obtained

\begin{tabular}{|c|c|c|c|c|c|c|c|c|c|c|c|c|c|}
\hline \multicolumn{7}{|c|}{ DATA TAKEN FROM TENSION TESTS } & \multicolumn{7}{|c|}{ DATA TAKEN FROM TORSIONTENSION TESTS } \\
\hline MATERIAL & \begin{tabular}{|l|} 
DATA \\
POINT \\
\end{tabular} & $\begin{array}{l}\text { TEST } \\
\text { TYPE }\end{array}$ & $\begin{array}{c}\sigma \\
\left(\mathrm{MPa}^{\mathrm{MPa}}\right.\end{array}$ & $\varepsilon$ & $\begin{array}{c}\dot{q} \\
\left(\mathrm{~s}^{-1}\right)\end{array}$ & $\begin{array}{l}\mathbf{T} \\
\text { (K) }\end{array}$ & MATERIAL & \begin{tabular}{|l|} 
DATA \\
POINT
\end{tabular} & $\begin{array}{l}\text { TEST } \\
\text { TYPE }\end{array}$ & $\begin{array}{c}\sigma \\
(\mathrm{MPa}) \\
\end{array}$ & $\boldsymbol{\varepsilon}$ & $\begin{array}{c}\dot{\varepsilon} \\
\left(\mathrm{s}^{-1}\right) \\
\end{array}$ & $\begin{array}{l}\mathrm{T} \\
(\mathrm{K})\end{array}$ \\
\hline OFHC COPPER & $\begin{array}{l}1 \\
2 \\
3 \\
4 \\
5\end{array}$ & $\begin{array}{c}\text { TENSION } \\
1\end{array}$ & $\begin{array}{l}60 \\
240 \\
430 \\
280 \\
170\end{array}$ & $\begin{array}{l}0.0 \\
0.2 \\
1.4 \\
0.2 \\
0.2\end{array}$ & $\begin{array}{c}0.002 \\
0.002 \\
0.002 \\
451 \\
464\end{array}$ & $\begin{array}{l}296 \\
296 \\
296 \\
307 \\
736\end{array}$ & OFHC COPPER & $\begin{array}{l}1 \\
2 \\
3 \\
4 \\
5\end{array}$ & $\left.\right|_{\text {TENSION }} ^{\text {TORSION }}$ & $\begin{array}{l}120 \\
270 \\
390 \\
310 \\
170\end{array}$ & \begin{tabular}{l|}
0.0 \\
0.5 \\
2.8 \\
0.2 \\
0.2
\end{tabular} & $\begin{array}{c}0.006 \\
0.006 \\
0.006 \\
85 \\
464\end{array}$ & $\begin{array}{l}296 \\
296 \\
296 \\
311 \\
736\end{array}$ \\
\hline ARMCO IRON & $\begin{array}{l}1 \\
2 \\
3 \\
4 \\
5\end{array}$ & TENSION & $\begin{array}{l}165 \\
335 \\
580 \\
500 \\
245\end{array}$ & $\begin{array}{l}0.0 \\
0.2 \\
1.7 \\
0.2 \\
0.2\end{array}$ & $\begin{array}{c}0.002 \\
0.002 \\
0.002 \\
407 \\
460\end{array}$ & $\begin{array}{l}296 \\
296 \\
296 \\
320 \\
744\end{array}$ & ARMCO IRON & $\begin{array}{l}1 \\
2 \\
3 \\
4 \\
5\end{array}$ & TORSION & $\begin{array}{l}130 \\
355 \\
545 \\
465 \\
245\end{array}$ & \begin{tabular}{l|}
0.0 \\
0.3 \\
2.3 \\
0.2 \\
0.2
\end{tabular} & $\begin{array}{c}0.006 \\
0.006 \\
0.006 \\
168 \\
460\end{array}$ & \begin{tabular}{l|}
296 \\
296 \\
296 \\
319 \\
744
\end{tabular} \\
\hline
\end{tabular}

Table 2. Constants for the four models using tension and torsion/tension data

\begin{tabular}{|c|c|c|c|c|c|c|c|c|c|c|c|c|c|c|c|c|c|}
\hline \multicolumn{8}{|c|}{ JOHNSON - COOK MODEL } & \multirow{2}{*}{\multicolumn{10}{|c|}{$\sigma=\left[A+B \varepsilon{ }^{n}\right]\left[1+C \ln \dot{\varepsilon}^{*}\right]\left[1-T^{*} m\right]$}} \\
\hline \multicolumn{8}{|c|}{ CONSTANTS OBTAINED FROM TENSION DATA } & \multicolumn{8}{|c|}{ CONSTANTS OBTAINED FROM TORSIONTTENSION DATA } & & \\
\hline MATERIAL & $\begin{array}{c}\mathrm{A} \\
(\mathrm{MPa})\end{array}$ & & $\begin{array}{c}\mathrm{B} \\
\mathrm{MPa} \text { ) }\end{array}$ & $\mathbf{n}$ & c & & $m$ & MATERIAL & $\begin{array}{c}\mathrm{A} \\
\langle\mathrm{MPa})\end{array}$ & $\begin{array}{c}\mathrm{B} \\
\mathrm{MPa}\end{array}$ & & n & & c & \multicolumn{3}{|c|}{ m } \\
\hline OFHC COPPER & 65 & \multirow{2}{*}{\multicolumn{2}{|c|}{$\begin{array}{l}356 \\
468\end{array}$}} & 0.37 & 0.013 & & 1.05 & OFHC COPPER & 145 & \multirow{2}{*}{$\begin{array}{l}230 \\
426\end{array}$} & \multirow{2}{*}{\multicolumn{2}{|c|}{$\begin{array}{l}0.34 \\
0.30\end{array}$}} & \multicolumn{2}{|c|}{0.034} & \\
\hline ARMCO IRON & 233 & & & 0.42 & 0.047 & & 0.42 & ARMCO IRON & 171 & & & & & 0.047 & \multicolumn{3}{|c|}{$\begin{array}{l}0.80 \\
0.47\end{array}$} \\
\hline \multicolumn{18}{|c|}{ MODIFIED JOHNSON - COOK MODEL $\quad \sigma=\left[A+B \varepsilon^{\mathrm{n}}\right]\left[\dot{\varepsilon}^{*} \mathrm{c}\right]\left[1-\mathrm{T}^{*} \mathrm{~m}\right]$} \\
\hline \multicolumn{8}{|c|}{ CONSTANTS OBTAINED FROM TENSION DATA } & \multicolumn{10}{|c|}{ CONSTANTS OBTAINED FROM TORSION/TENSION DATA } \\
\hline MATERIAL & $\begin{array}{c}\mathrm{A} \\
(\mathrm{MPa})\end{array}$ & & $\begin{array}{c}\mathrm{B} \\
\mathrm{MPa}\end{array}$ & $\mathbf{n}$ & c & & m & MATERIAL & $\stackrel{\mathrm{A}}{\mathrm{APa}}$ & $\begin{array}{r}B \\
\mathrm{MPa} \\
\end{array}$ & & $n$ & & c & \multicolumn{3}{|c|}{$\mathbf{m}$} \\
\hline OFHC COPPER & 65 & \multirow{2}{*}{\multicolumn{2}{|c|}{$\begin{array}{l}354 \\
449\end{array}$}} & 0.37 & 0.013 & \multirow{2}{*}{\multicolumn{2}{|c|}{$\begin{array}{l}1.05 \\
0.42\end{array}$}} & OFHC COPPER & 144 & \multirow{2}{*}{\multicolumn{2}{|c|}{$\begin{array}{l}227 \\
415\end{array}$}} & .34 & \multicolumn{2}{|c|}{0.035} & \multicolumn{3}{|c|}{0.78} \\
\hline ARMCO IRON & 223 & & & 0.42 & 0.048 & & & ARMCO IRON & 167 & & & .30 & & 0.049 & & 0.46 & \\
\hline \multicolumn{8}{|c|}{ COMBINED MODEL } & \multicolumn{10}{|c|}{$\sigma=\left[A+B \varepsilon^{n}\right]\left[E X P\left(-C_{3} T+C_{4} T \operatorname{In} \varepsilon\right)\right]$} \\
\hline \multicolumn{8}{|c|}{ CONSTANTS OBTAINED FROM TENSION DATA } & \multicolumn{10}{|c|}{ CONSTANTS OBTAINED FROM TORSION/TENSION DATA } \\
\hline MATERIAL & $\begin{array}{c}\mathrm{A} \\
(\mathrm{MPa})\end{array}$ & & $\begin{array}{l}\mathrm{B} \\
\mathrm{MPa} \text { ) }\end{array}$ & $\mathbf{n}$ & $c_{3}$ & & $c_{4}$ & MATERIAL & $\stackrel{\mathrm{A}}{\mathrm{A} \text { a) }}$ & $\begin{array}{r}B \\
\angle M P a \\
\end{array}$ & & $n$ & & $c_{3}$ & \multicolumn{3}{|c|}{$c_{4}$} \\
\hline OFHC COPPER & 100 & \multirow{2}{*}{\multicolumn{2}{|c|}{$\begin{array}{l}545 \\
856\end{array}$}} & 0.37 & 0.00145 & \multirow{2}{*}{\multicolumn{2}{|c|}{$\begin{array}{l}0.000046 \\
0.000122\end{array}$}} & OFHC COPPER & 279 & \multirow{2}{*}{$\begin{array}{l}442 \\
793\end{array}$} & \multirow{2}{*}{\multicolumn{2}{|c|}{$\begin{array}{l}0.34 \\
0.30\end{array}$}} & & 0226 & \multirow{2}{*}{\multicolumn{3}{|c|}{$\begin{array}{l}0.000115 \\
0.000127\end{array}$}} \\
\hline ARMCO IRON & 425 & & & 0.42 & 0.00244 & & & ARMCO IRON & 319 & & & & & 0238 & & & \\
\hline ZERILLI - ARMS & & MODEL & & & & & & $\begin{array}{l}\left.\sigma=C_{0}+C_{2} \varepsilon^{n}\right] \\
\sigma=c_{0}+c_{1}[E X\end{array}$ & $\begin{array}{l}X P\left(-C_{3}\right. \\
\left(-C_{3} T\right.\end{array}$ & $\begin{array}{l}T+C_{4} T \\
C_{4} T \ln \varepsilon \\
\end{array}$ & $\begin{array}{l}\ln \hat{\varepsilon})] \\
\partial]+c_{3} \varepsilon\end{array}$ & & & fec & & & \\
\hline CONSTANTSO & TAINED & FROM & TENSI & ONDATA & & & & CONSTANTS OBTA & VED FROI & TOASIOI & TENSION & NDAT & & & & & \\
\hline MATERIAL & $\begin{array}{c}\mathrm{C}_{0} \\
\text { (MPa) }\end{array}$ & $\begin{array}{c}C_{1} \\
\text { (MPa) } \\
\end{array}$ & 1) $\begin{array}{c}\mathrm{C}_{2} \\
(\mathrm{MPa})\end{array}$ & $\begin{array}{c}C_{3} \\
(K-1)\end{array}$ & $\begin{array}{c}c_{4} \\
(K-1)\end{array}$ & \begin{tabular}{|c|}
$\mathrm{Cs}$ \\
$\mathrm{MPa})$ \\
$\mathrm{M}$
\end{tabular} & $\mathbf{n}$ & MATERIAL & $\begin{array}{c}\mathrm{C}_{0} \\
(\mathrm{MPa})\end{array}$ & \begin{tabular}{|c|}
$c_{1}$ \\
(MPa)
\end{tabular} & $\begin{array}{c}\mathrm{C}_{2} \\
\text { (MPa) }\end{array}$ & & & $\begin{array}{c}c_{4} \\
(K-1) \\
(K\end{array}$ & & $\begin{array}{c}\mathrm{C}_{5} \\
(\mathrm{MPa}) \\
\end{array}$ & n \\
\hline OFHC COPPER & 60 & - & 656 & 0.00198 & 0.000060 & - & 0.37 & OFHC COPPER & 120 & - & 1063 & 0.0 & 9472 & 0.0002 & & 一 & 0.34 \\
\hline ARMCO IRON & 65 & 3214 & 4 & 0.00973 & 0.000321 & 332 & 0.42 & ARMCO IRON & 65 & ... & - & & & & & ... & \\
\hline
\end{tabular}




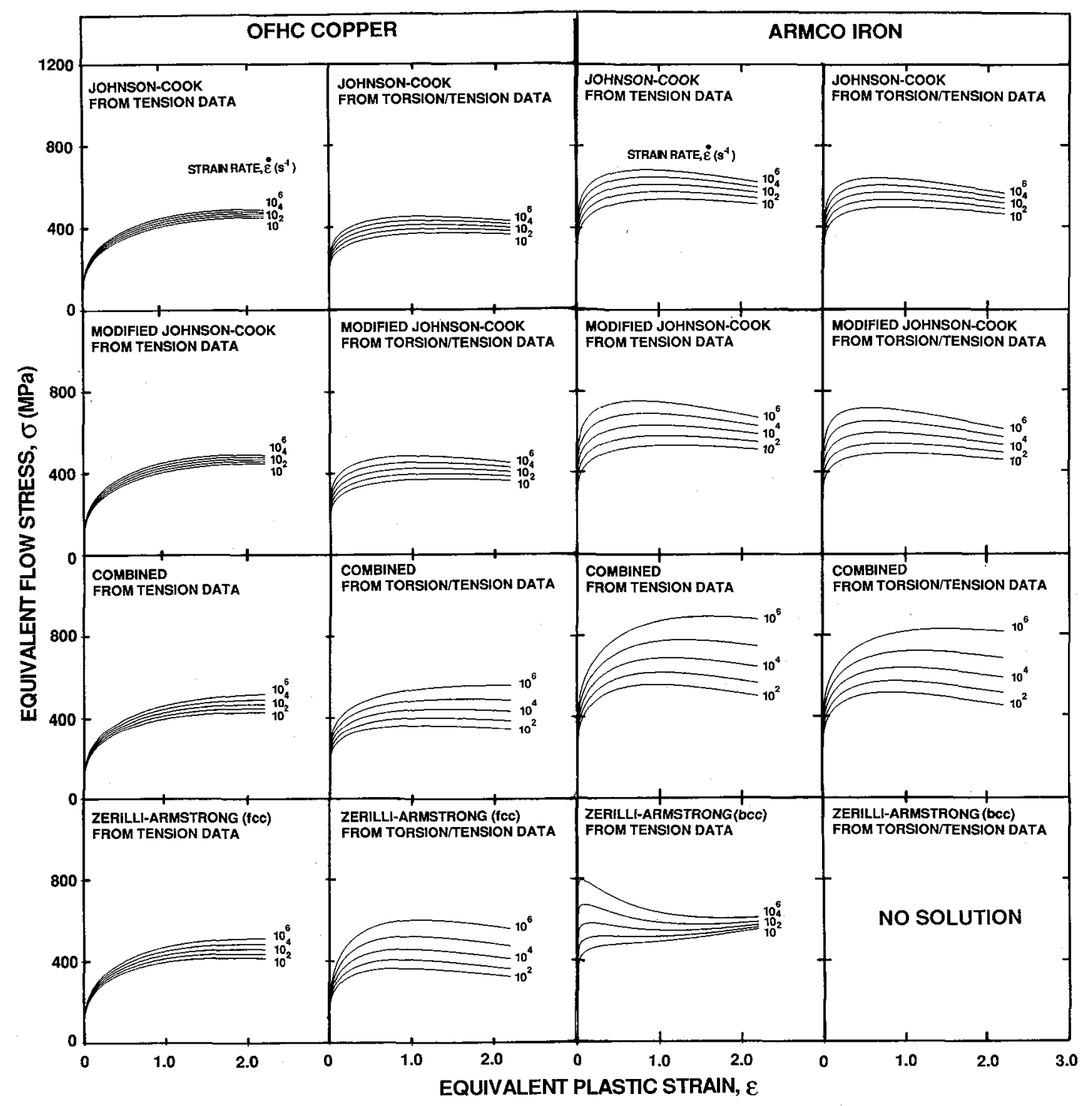

Figure 2. Adiabatic stress-strain relationships for OFHC copper and Armco iron, using various models and constants

\section{COMPARISON OF MODEL PREDICTIONS TO CYLINDER IMPACT TEST DATA}

An assessment of the models can be made by comparing computed predictions of cylinders impacting rigid surfaces to corresponding test data $/ 1$. Cylinder impact experiments provide an independent tool to evaluate the models, because they experience relatively high strains, high strain rates, and elevated temperatures. To quantify the degree of agreement between computed shapes and test shapes, an average error is defined as

$$
\bar{\Delta}=\frac{1}{3}\left[\frac{|\Delta \mathrm{L}|}{\mathrm{L}_{\mathrm{T}}}+\frac{|\Delta \mathrm{D}|}{\mathrm{D}_{\mathrm{T}}}+\frac{|\Delta \mathrm{W}|}{\mathrm{W}_{\mathrm{T}}}\right]
$$

where $\mathrm{L}_{\mathrm{T}}, \mathrm{D}_{\mathrm{T}}$, and $\mathrm{W}_{\mathrm{T}}$ are the deformed length, diameter, and bulge (diameter at $0.2 \mathrm{~L}_{\mathrm{o}}$ from impact end) measured from the test specimens, and $\Delta \mathrm{L}, \Delta \mathrm{D}$, and $\Delta \mathrm{W}$ are the differences between the computed and test results. 


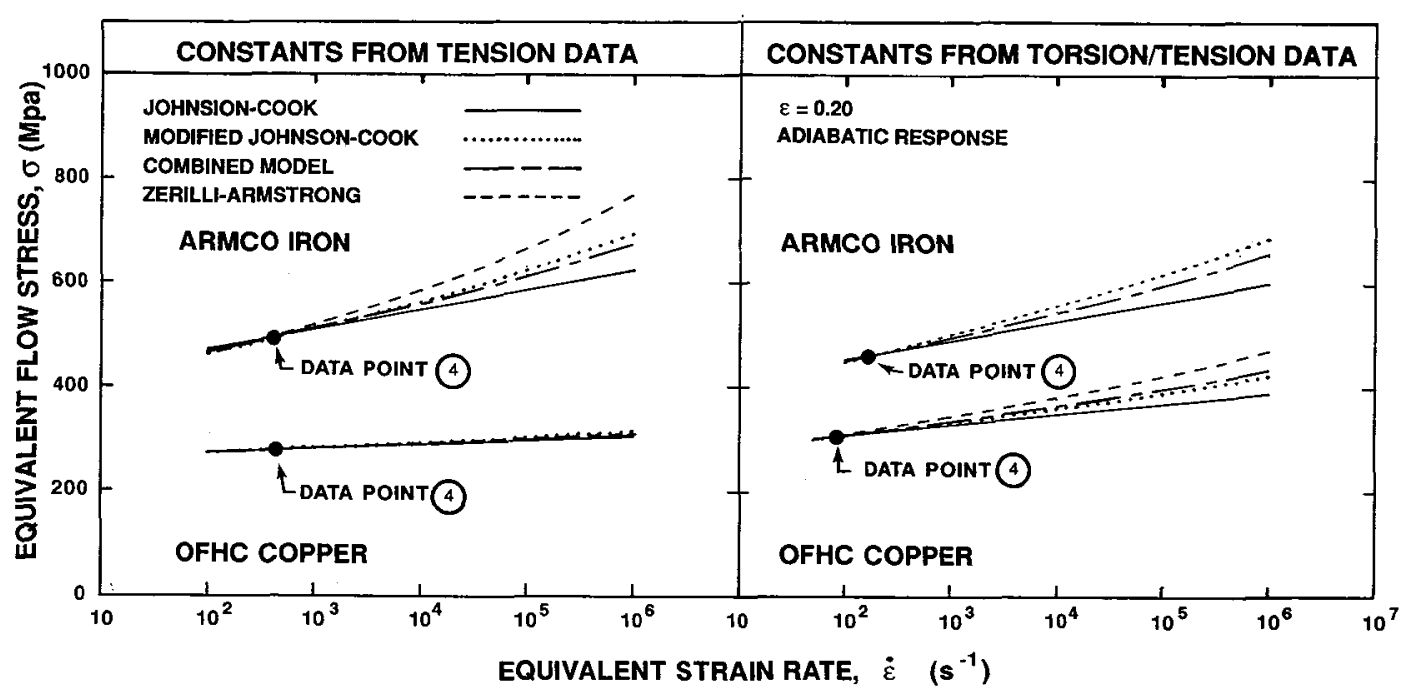

Figure 3. Stress-strain rate relationships for OFHC copper and Armco iron, using various models and constants

Figure 4 presents comparisons between the computed results and the test results for OFHC copper and Armco iron. Models using the tension data constants generally performed better than the models using the torsion/tension data constants. This is particularly true for OFHC copper. The $\bar{\Delta}^{\prime}$ s, from Figure 4 , are documented in Table 3 . There appears to be little performance difference between the four models, though there is an obvious difference between the two sets of constants used.

In order to evaluate these models, using cylinder impact experiments, an understanding of the strains and strain rates occurring in these tests must be known. To have agreement with cylinder-impact tests does not necessarily ensure that the model is accurate at all strains and strain rates, but rather indicates the accuracy at the strains and strain rates that occur during a cylinder impact test. Figure 5 shows the strains occurring in the two cylinder impact experiments and the strain rates that produced those strains. These results were generated with the Johnson-Cook model, using the constants obtained from tension data. For the OFHC copper test, over 80 percent of the material experiences a strain of only 0.8; and for the Armco iron, the strain is smaller. The strain rates which induce these strains are consistently on the order of $10^{3} \mathrm{~s}^{-1}$ to $10^{5} \mathrm{~s}^{-1}$. This information provides a guide when evaluating material models using cylinder impact experiments. The models can only be accurately evaluated within the strains and strain rates that occur in a cylinder impact experiment. Figure 5 indicates the models can be adequately evaluated for strains up to approximately 0.8 and for strain rates between $10^{3} \mathrm{~s}^{-1}$ and $10^{5} \mathrm{~s}^{-1}$.

\section{SUMMARY AND CONCLUSIONS}

This paper has presented an explicit technique to obtain constants for constitutive models using a consistent set of material test data for the purpose of making comparisons between various constitutive models. Constants were developed for four models using this technique. A comparison was made between these models by simulating cylinder impact experiments. Some conclusions are as follows:

(a) Constants can be obtained in a simple, straightforward manner, for a variety of constitutive model formulations, using this technique.

(b) Constitutive models may need to be revised to a consistent number of material constants to make comparisons legitimate.

(c) All four models show generally good agreement with cylinder impact experiments when using data generated from tension tests.

(d) When using cylinder impact experiments to determine constitutive model performance, the comparisons are only valid for the strains and strain rates experienced in these experiments. For this study, the strains were 0 to 0.8 and the strain rates were $10^{3} \mathrm{~s}^{-1}$ to $10^{5} \mathrm{~s}^{-1}$. Experiments that would increase this range would be desirable.

(e) Constants obtained using the tension data performed consistently better than those obtained using the torsion/tension data as shown in Table 3. This is probably due to the fact that most of the deformation in a cylinder impact experiment is compression, and not shear, and that materials do not always obey the von Mises flow rule.

\section{Acknowledgement.}

This work was funded by an Alliant Techsystems Independent Research and Development program. 
OFHC COPPER
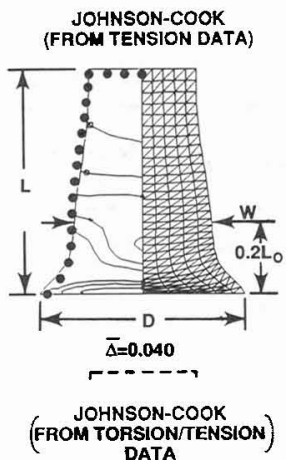
ATA

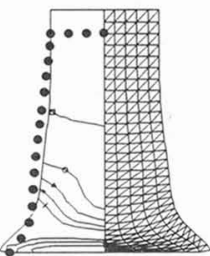

$\bar{\Delta}=0.102$
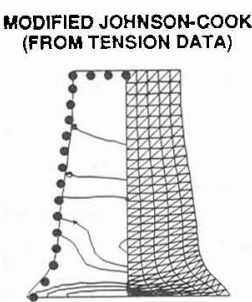

$\bar{\Lambda}=0.038$

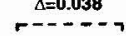

MODIFIED JOHNSON-COOK
(FROM TORSION/TENSION) (FROM TORSION/TENSION
DATA

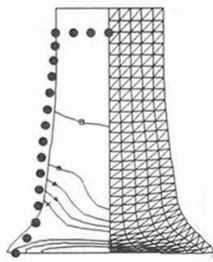

$\bar{\Delta}=0.099$

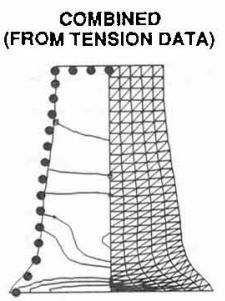

$\bar{\Delta}=0.040$

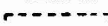

COMBINED
(FROM TORSION/TENSION)
DATA

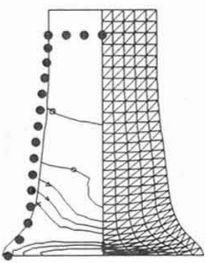

$\bar{\Delta}=0.086$
ZERELLI-ARMSTRONG (FROM TENSION DATA)

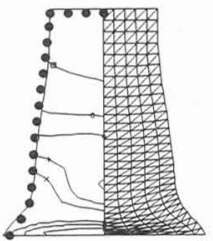

$\bar{\Delta}=0.037$

ZERILLI-ARMSTRONG (FROM TORSION/TENSION)

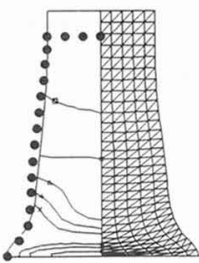

$\bar{\triangle}=0.069$

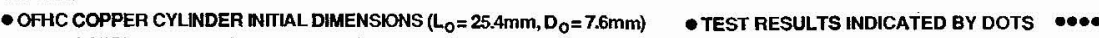
- OFHC COPPER CLYNDER TEST DMENSIONS $\left(\mathrm{L}_{T}=16.2 \mathrm{~mm}, D_{T}=13.5 \mathrm{~mm}, W_{T}=10.1 \mathrm{~mm}\right) \quad \bullet \cdot 1 \mathrm{APACT}$ VELOCTY $=190 \mathrm{~m} / \mathrm{s}$

ARMCO, IRON

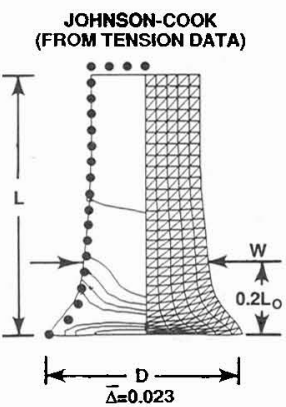

r.....-

JOHNSON-COOK (FROM TORSIONTENSION)

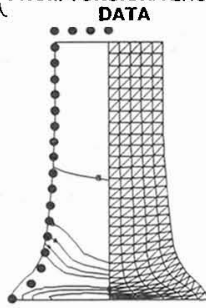

$\bar{\Delta}=0.043$

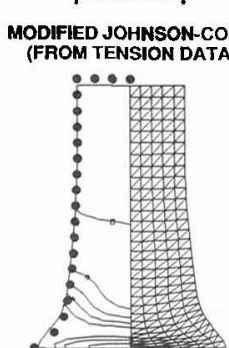

$\bar{\Delta}=0.028$

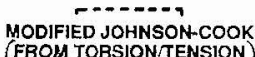

(FROM TORSIONTENSION)

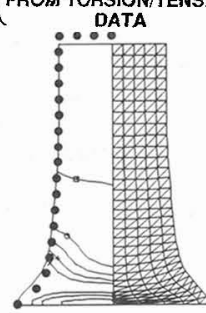

$\bar{\Delta}=0.019$
COMBINED (FROM TENSION DATA)

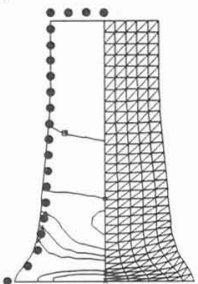

$\bar{\Delta}=0.055$

(2............

COMBINED
(FROM TORSIONTENSION)
DATA

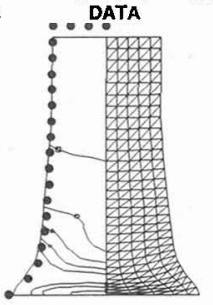

$\bar{\Delta}=0.045$

NOTES:

- ARMCOIRON CYLNDER INTIAL DIMENSIONS $\left(L_{0}=25.4 \mathrm{~mm}, D_{0}=7.6 \mathrm{~mm}\right) \quad$ - IMPACT VELOCTY $=221 \mathrm{~m} / \mathrm{s}$

- ARMCOIRON CYLNDER TEST DIMENSIONS $\left(L_{T}=19.8 \mathrm{~mm}, D_{T}=13.7 \mathrm{~mm}, W_{T}=8.6 \mathrm{~mm}\right)$

Figure 4. Comparison of computed results and test data for OFHC copper and Armco iron cylinder impact tests 
Table 3. Summary of differences between computed results and test data, $\bar{\Delta}$, for four material models using tension and torsion/tension data

\begin{tabular}{|c|c|c|c|c|c|c|c|}
\hline \multirow[b]{2}{*}{ MODEL } & \multicolumn{2}{|c|}{ OFHC COPPER } & \multicolumn{2}{|c|}{ ARMCO IRON } & \multicolumn{3}{|c|}{ AVERAGE $\bar{\Delta}$} \\
\hline & $\bar{\Lambda}_{\text {TENSION }}$ & $\begin{array}{c}\bar{\Delta} \\
\text { TORSION/ } \\
\text { TENSION }\end{array}$ & $\bar{\Delta}_{\text {TENSION }}^{\bar{\Delta}}$ & $\begin{array}{c}\bar{\Delta} \\
\text { TORSION/ } \\
\text { TENSION }\end{array}$ & TENSION & $\begin{array}{l}\text { TORSION/ } \\
\text { TENSION }\end{array}$ & BOTH SETS \\
\hline JOHNSON-COOK & 0.040 & 0.102 & 0.023 & 0.043 & 0.032 & 0.073 & 0.053 \\
\hline MODIFIED JOHNSON-COOK & 0.038 & 0.099 & 0.028 & 0.019 & 0.033 & 0.059 & 0.046 \\
\hline COMBINED & 0.040 & 0.086 & 0.055 & 0.045 & 0.048 & 0.066 & 0.057 \\
\hline ZERILLI-ARMSTRONG & 0.037 & 0.069 & 0.034 & $\begin{array}{c}\text { NO } \\
\text { SOLUTION }\end{array}$ & 0.036 & - & - \\
\hline
\end{tabular}

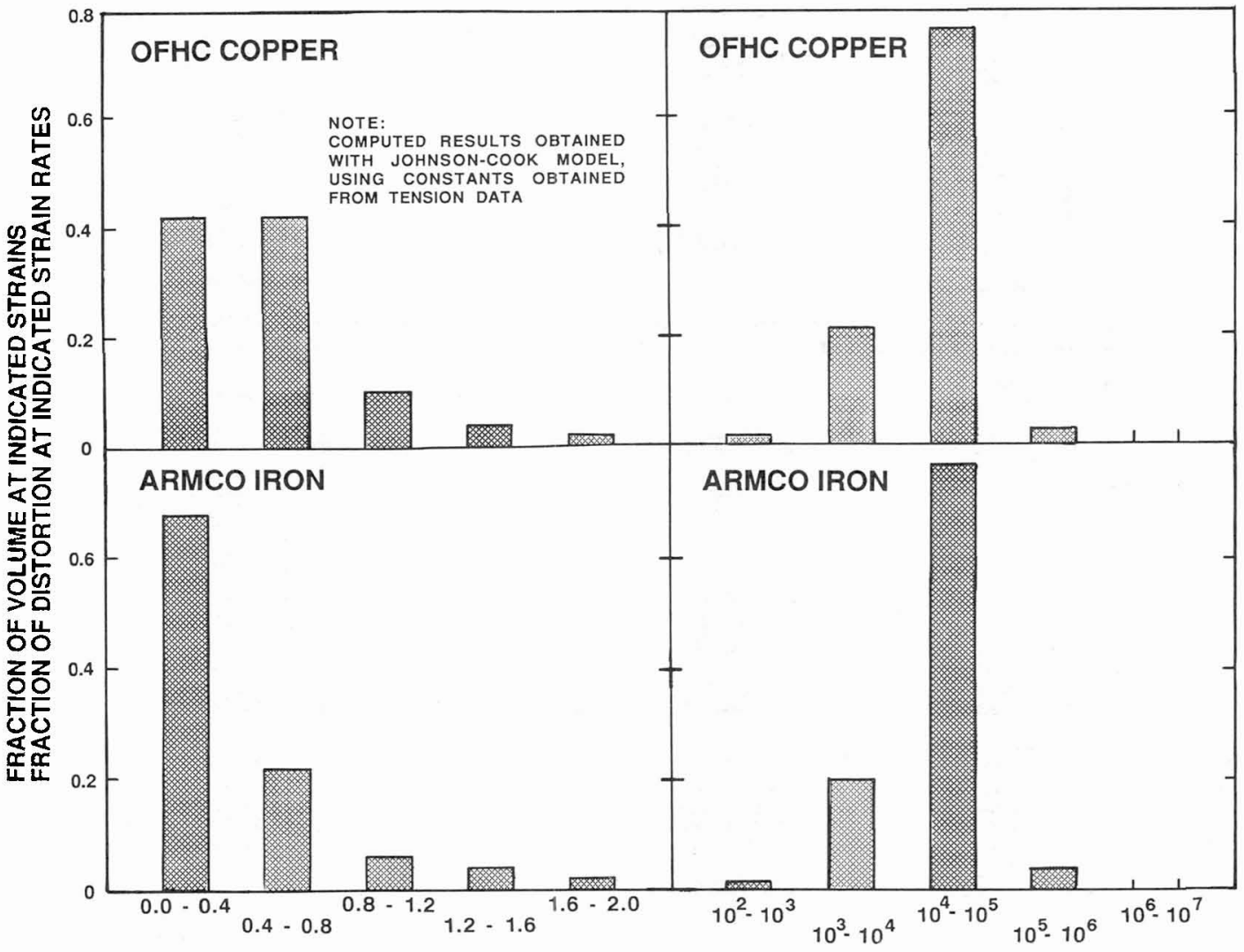

EQUIVALENT PLASTIC STRAIN, $\varepsilon$

EQUIVALENT PLASTIC STRAIN RATE, $\dot{\varepsilon}\left(\mathrm{s}^{-1}\right)$

Figure 5. Computed distribution of strain and strain rates, in the cylinder impact test, for OFHC copper and Armco iron

\section{REFERENCES}

/1/ JOHNSON, G. R. and W. H. Cook, Proceedings of the Seventh International Symposium on Ballistics (The Hague, The Netherlands, 1983), p. 541.

121 ZERILLI, F. J. and R. W. Armstrong, J. Appl. Phys. 61 (5), 1 March 1987, p. 1816.

13/ FOLLANSBEE, P. S., G. Regazzoni and U. F. Kocks, Institute of Physics, Lonđon, U. K., 1984.

14 NADAI, A. and M. J. Manjoine, Appl. Mcch., June 1941.

15/ BRIDGMAN, P. W, McGraw-Hill, 1952. 